\title{
Complex High Turnover in Bone Metabolism Impairs Bone Quality in Female Long-Distance Runners with Menstrual Disorders
}

\author{
Eiji Sasaki ${ }^{1}$, Yuki Fujita ${ }^{1}$, Katsuro Yoneda ${ }^{2}$, Shoko Kinugasa ${ }^{3}$, Ken Kato ${ }^{4}$, Eiichi Tsuda ${ }^{1}$, Yasuyuki \\ Ishibashi ${ }^{1}$ and Takashi Umeda ${ }^{2}$
}

${ }^{1}$ Department of Orthopedic Surgery, Hirosaki University Graduate School of Medicine, Japan

${ }^{2}$ Meijo University, Japan

${ }^{3}$ Public Health Center, Okazaki Medical Association, Japan

${ }^{4}$ Milk Science Research Institute, Megmilk Snow Brand Co Ltd, Japan

*Corresponding author: Eiji Sasaki, MD, PhD, Department of Orthopaedic Surgery, Hirosaki University Graduate School of Medicine, 5 Zaifu-cho, Hirosaki, Aomori 036-8562, Japan, Tel: +81-172-39-5083, Fax: +81-172-36-3826

\begin{abstract}
Objectives: Menstrual disorder is a risk factor for stress fracture. Stress fractures impede running activity in female long-distance runners. However, the bone metabolism of female long-distance runners, and its relationship with bone quality, are not understood. We examined the characteristics of bone metabolism and bone quality in female long-distance runners with menstrual disorder.
\end{abstract}

Methods: Sixteen female university long-distance runners and 31 young female non-athlete volunteers were enrolled. Self-reported menstrual condition was recorded. Serum estradiol, collagen type 1 cross-linked N-telopeptide (NTx), propeptide of procollagen type I (P1NP) and pentosidine concentrations were measured and compared between the groups. Factors associated with serum pentosidine concentration were examined by regression analysis.

Results: Fifteen (93.8\%) athletes and five (16.3\%) controls had a menstrual disorder $(p<0.001)$. Serum NTx $(p<$ $0.001)$, total P1NP $(p=0.010)$ and pentosidine $(p<0.001)$ concentrations were significantly higher in athletes. There was a positive correlation between serum NTx and total P1NP concentrations $(\rho=0.448, p=0.002)$. Multivariate linear regression analysis identified a significant positive correlation between serum pentosidine and NTx concentrations $(p=0.030)$, and negative correlations between serum pentosidine and serum estradiol $(p=0.035)$ and total P1NP $(p=0.030)$ concentrations.

Conclusion: Markers of bone absorption and formation were elevated in female long-distance runners with menstrual disorder compared with healthy controls, and there were positive correlations between the markers. The com plex high state was distinct to female long-distance runners with menstrual disorder, and higher bone absorption impaired bone quality.

\section{Introduction}

Female athletes are at risk of menstrual disorder and osteoporosis as a result of the relative energy deficiency caused by their sporting activities [1,2]. Stress fracture occurs when there is an imbalance between bone formation and bone absorption as a result of repeated cyclic loading [3], which is common in female athletes and may prevent them from running for prolonged periods. The prevalence of stress fracture is significantly higher in female long-distance runners than women who participate in other sports $[4,5]$, its incidence is reportedly as high as $50 \%$ per year [6]. Female athletes are at risk as a result of reduced bone mineral density, low body weight and chronic menstrual disorders [7-9]. Low body weight and fat content are critical for elite endurance athletes. It has been challenging to identify athletes at high risk for stress fracture so as to prevent them, because the underlying pathophysiologic mechanisms causing stress fracture remain elusive [10].

Bone metabolic markers are attracting an increasing amount of attention as objective tools for the

Citation: Sasaki E, Fujita Y, Yoneda K, Kinugasa S, Kato K, et al. (2019) Complex High Turnover in Bone Metabolism Impairs Bone Quality in Female Long-Distance Runners with Menstrual Disorders. Int J Sports Exerc Med 5:152. doi.org/10.23937/2469-5718/1510152

Accepted: November 07, 2019; Published: November 09, 2019

Copyright: (C) 2019 Sasaki E, et al. This is an open-access article distributed under the terms of the Creative Commons Attribution License, which permits unrestricted use, distribution, and reproduction in any medium, provided the original author and source are credited. 
monitoring of bone condition. Conventional evaluation techniques such as Bone Mineral Density (BMD), micro-computed tomography, scintigraphy and magnetic resonance imaging are well-established means of diagnosing stress fracture [11-13], but do not reflect the metabolic condition of bone. It has been reported, however, there is a relationship between high bone absorption and stress fracture in athletes [14], raising the possibility that athletes at risk of stress fracture could be identified before they were affected, and preventative measures put in place. Nevertheless, there is conflicting evidence that bone metabolic markers do not predict stress fracture in combat [15]. The inconsistency of the evidence has meant that bone metabolic markers are not routinely used in clinical practice, but we hypothesized that they may help illuminate the etiology and mechanism of stress fracture in elite long-distance runners.

It is well recognized that bone quality contributes to bone strength as much as bone mineral density [16]. Postmenopausal women with primary osteoporosis have lower bone mineral density, and elevated serum pentosidine (SPEN) concentration, compared with agematched controls without osteoporosis [17]. Poor bone quality is reportedly significantly associated with the incidence of femoral fractures, even if BMD is adequate [18]. Few studies have investigated bone quality in athletes, although there has been a report suggesting that there is a relationship between some (but not all) bone quality markers and history of stress fracture in elite university lacrosse players [19]. The nature of the relationship between bone metabolism in female athletes and bone quality remains unclear.

A fuller understanding of bone metabolism and bone condition in female athletes would illuminate the underlying mechanisms of stress fracture, and may allow stress fracture to be predicted, and thus avoided. We undertook a study to investigate the influence of menstrual disorder on systemic bone metabolic markers and bone quality markers in female long-distance runners, due to their high risk of stress fracture, and compare these with healthy female volunteers as a control group. We also sought to examine the relationship between bone metabolic markers and bone quality markers. We hypothesized that female long-distance runners would have specific bone metabolism features that influenced bone quality, and that these would be influenced by menstrual disorders.

\section{Methods}

\section{Subjects}

We enrolled 19 elite female long-distance runners belonging to the ekiden club of our institution, and 32 healthy young women who had volunteered to participate in the Iwaki Health Promotion Project, having responded to mass media advertisements and been recruited by public health nurses. The Iwaki Health Promotion Project is a community-based preventative medicine program that aims to improve life expectancy by performing general health check ups and prophylactic interventions [20-22]. Female long-distance runners were defined as the athlete group, and the volunteers as the control group. In the athlete group, three subjects under treatment for fracture or menstrual disorders by hormone or oral contraceptive supplementation were excluded. Subjects in the control group were aged $18-25$ years; one was excluded as she was taking an oral contraceptive. UItimately, there were 16 subjects in the athlete group and 31 in the control group. The study was conducted in May 2015 in athlete group, and May 2014 and May 2015 in the control group. All participants gave written, informed consent to participate, and the study was conducted with the approval of our institutional ethics committee.

Demographic data, including height and weight, were measured in all subjects by the investigators, and Body Mass Index (BMI) was calculated. The percentage of fat volume per body weight ( $\%$ fat) was estimated by the impedance method (MC-190, Tanita Co. Ltd., Tokyo, Japan). The history of stress fracture was established by means of a self-reported questionnaire regarding fracture site and frequency.

\section{Biochemical examination}

Fasting venous blood specimens were taken from all subjects in the early morning for biochemical examination. Serum was obtained by centrifugation, separated into aliquots and stored at $-80{ }^{\circ} \mathrm{C}$ for later analysis. The serum concentrations of the following gonadotropins were examined; luteinizing hormone ( $\mathrm{LH}, \mathrm{mIU} / \mathrm{ml}$ ); follicle stimulating hormone (FSH, mIU/ $\mathrm{ml})$, prolactin $(\mathrm{ng} / \mathrm{ml})$, estradiol $(\mathrm{pg} / \mathrm{ml})$ and testosterone $(\mathrm{ng} / \mathrm{ml})$ by our institution's clinical laboratory. Bone metabolism markers consisted of indices of bone absorption, bone formation and bone quality markers, in addition to serum calcium (mg/dl) and inorganic phosphate $(\mathrm{mg} / \mathrm{dl})$ concentrations. The bone absorption marker was serum type I collagen crosslinked N-telopeptide (sNTx, nM bone collagen equivalents/I $(B C E / I))$ concentration, measured by enzyme immunoassay. The bone formation marker was total $\mathrm{N}$-terminal propeptide of procollagen type I (P1NP, $\mu \mathrm{g} / \mathrm{I})$ concentration, also measured by enzyme immunoassay. The bone quality marker was serum pentosidine (sPEN, pmol/ml) concentration, measured by high performance liquid chromatography. We referred to Japanese Osteoporosis Society guidelines for the normal ranges of SNTx (7.5-16.5 nM BCE/I) and sP1NP (14.9-68.8 $\mu \mathrm{g} / \mathrm{l})$ [23].

\section{Bone mineral density measurement}


Bone mineral density was measured by the Dual-Energy X-Ray Absorptiometry (DEXA) method. In a pilot study in the athlete group, we investigated the relationship between serum estradiol concentration and BMD in the lumbar vertebral body, femoral neck and distal radius. Spearman's correlation analysis identified correlation coefficients of $0.45(p=0.082)$ in the lumbar vertebral body, $0.53(p=0.034)$ in the femoral neck and 0.69 $(p<0.001)$ in the distal radius. Consequently, we judged that BMD in the distal radius most strongly reflected the gonadotropic status, and adopted it for further analyses (Table 1).

\section{Menstruation status}

Menstruation status was surveyed by self-reported questionnaire. Presence or absence of menstruation, cycle length, regularity, first menstruation and oral contraceptive use were recorded. We defined normal menstruation as regular menstruation in a cycle of 25-38 days, and irregular menstruation as a delayed menstruation cycle from 39 days to 3 months. Primary amenorrhea was defined as never having menstruated, and secondary amenorrhea was defined as absence of menstruation for $>3$ months [24].

\section{Statistical analysis}

We performed power analysis to estimate the sample size sufficient for regression analysis of the concentrations of SNTX and sPEN using data from another pilot study of 16 healthy young female participants in the Iwaki Health Promotion Project in 2014. These data indicated that the Standard Deviation (SD) of the $\mathrm{x}$-axis was 3.37 , and the SD of the regression

Table 1: Relationship between serum estradiol concentration and bone mineral density in lumbar vertebra, femur and distal radius.

\begin{tabular}{|l|l|l|}
\hline & \multicolumn{2}{|l|}{ Serum estradiol concentration } \\
\hline & $\rho$ & $p$-value \\
\hline Lumbar vertebra & 0.45 & 0.082 \\
\hline Femoral neck & 0.53 & 0.034 \\
\hline Distal radius & 0.69 & $<0.001$ \\
\hline
\end{tabular}

Spearman's correlation coefficients between bone mineral density and serum estradiol concentration were calculated in the athlete group as a pilot study. errors was 5.59. If the true slope of the line obtained by regressing the concentration of SPEN against that of SNTx was 0.888 , we would have needed to study 29 subjects to be able to reject the null hypothesis that the slope equalled zero with a probability (power) of 0.8. The type I error associated with this test of the null hypothesis was 0.05 . As 47 subjects were enrolled to this study, we were able to reject the null hypothesis with a power of 0.999 [25].

The demographic and biologic data of the athlete and control groups were compared using the Mann-Whitney $U$ test. The proportions reporting each menstrual disorder were compared by the chisquared test. Spearman's correlation coefficient $(\rho)$ was calculated to examine the relationship between sNTx and P1NP concentrations to examine the extent of their contribution to bone metabolic turnover. The BMD in the distal radius was examined according to participants' menstruation status, and compared using analysis of variance (ANOVA) and Tukey's post hoc test. To identify risk factors for impaired bone quality, linear regression analysis was performed with the SPEN concentration as the dependent variable, and age, BMI, and serum gonadotropin and bone metabolism marker concentrations as dependent variables. Data input and analyses were undertaken with SPSS (version 12.0J, SPSS Inc., Chicago, IL, USA). A p-value $<0.05$ was considered statistically significant.

\section{Results}

The mean age of the athletes was $19.7 \pm 1.1$ years, compared with $22.7 \pm 1.6$ years in the control group ( $p$ $<0.001$ ). Long-distance runners had significantly lower body weight $(p<0.001)$, lower BMI $(p<0.001)$ and lower $\%$ fat $(p<0.001)$ than controls (Table 2$)$. Three subjects in the athlete group (17.6\%) reported a history of stress fracture. Indeed, these athletes reported multiple incidences of stress fracture, affecting the fibula, metatarsal, sacrum, tibia and navicular. Fifteen of the 16 athletes $(93.8 \%)$ reported menstrual disorders, compared with $16.1 \%$ of the control group ( $p<0.001$, Table 3$)$. Six athletes had irregular menstruation, seven secondary amenorrhea and two primary amenorrhea. Mean age at first menstruation (excluding those with primary amenorrhea) was significantly delayed by 3 years in the ath-

Table 2: Demographic data of subjects.

\begin{tabular}{|l|l|l|l|}
\hline & Control & Athlete & p-value \\
\hline Sample number & 31 & 16 & - \\
\hline Age $($ y.o.) & $22.7 \pm 1.6$ & $19.7 \pm 1.1$ & $<0.001$ \\
\hline Height $(\mathrm{cm})$ & $157.4 \pm 6.2$ & $158.8 \pm 5.2$ & 0.363 \\
\hline Body weight $(\mathrm{kg})$ & $51.8 \pm 6.8$ & $44.9 \pm 4.6$ & $<0.001$ \\
\hline BMl $\left(\mathrm{kg} / \mathrm{m}^{2}\right)$ & $21.0 \pm 3.1$ & $17.8 \pm 1.2$ & $<0.001$ \\
\hline$\%$ fat $(\%)$ & $28.4 \pm 6.7$ & $15.2 \pm 4.6$ & $<0.001$ \\
\hline
\end{tabular}

Data are presented as the mean \pm standard deviation. The Mann-Whitney $U$ test was performed to compare groups. A p-value $<$ 0.05 was considered significant. Abbreviation: BMI: Body Mass Index. 
Table 3: Comparison of gonadotropin, bone metabolism markers and bone quality markers in athlete and control groups.

\begin{tabular}{|l|l|l|l|}
\hline & Control & Athlete & p-value \\
\hline Gonadotropin concentration & & & \\
\hline LH $(\mathrm{mlU} / \mathrm{ml})$ & $6.4 \pm 7.6$ & $3.9 \pm 3.3$ & 0.281 \\
\hline FSH $(\mathrm{mlU} / \mathrm{ml})$ & $4.3 \pm 2.5$ & $5.3 \pm 2.5$ & 0.217 \\
\hline Prolactin $(\mathrm{ng} / \mathrm{ml})$ & $20.4 \pm 16.4$ & $8.6 \pm 2.2$ & $<0.001$ \\
\hline Estradiol $(\mathrm{pg} / \mathrm{ml})$ & $80.5 \pm 61.9$ & $20.8 \pm 10.5$ & $<0.001$ \\
\hline Testosterone $(\mathrm{ng} / \mathrm{ml})$ & $0.4 \pm 0.1$ & $0.4 \pm 0.1$ & 0.225 \\
\hline Menstrual status & & & \\
\hline Normal menstruation & $26(83.9 \%)$ & $1(6.3 \%)$ & \\
\hline Irregular menstruation & $5(16.1 \%)$ & $6(37.4 \%)$ & 0.001 \\
\hline Secondary amenorrhea & $0(0 \%)$ & $7(43.8 \%)$ & \\
\hline Primary amenorrhea & $0(0 \%)$ & $2(12.5 \%)$ & $<0.001$ \\
\hline First menstruation (y.o.) & $11.9 \pm 1.2$ & $14.8 \pm 2.0$ & \\
\hline
\end{tabular}

Gonadotropin values are presented as the mean \pm standard deviation. Values in parentheses indicate the proportion (\%) in each group. The concentrations of gonadotropin were compared using the Mann-Whitney $U$ test. The proportions reporting menstrual disorders were compared using the chi-square test. A p-value $<0.05$ was considered significant.

Abbreviations: LH: Luteinizing Hormone; FSH: Follicle Stimulating Hormone.

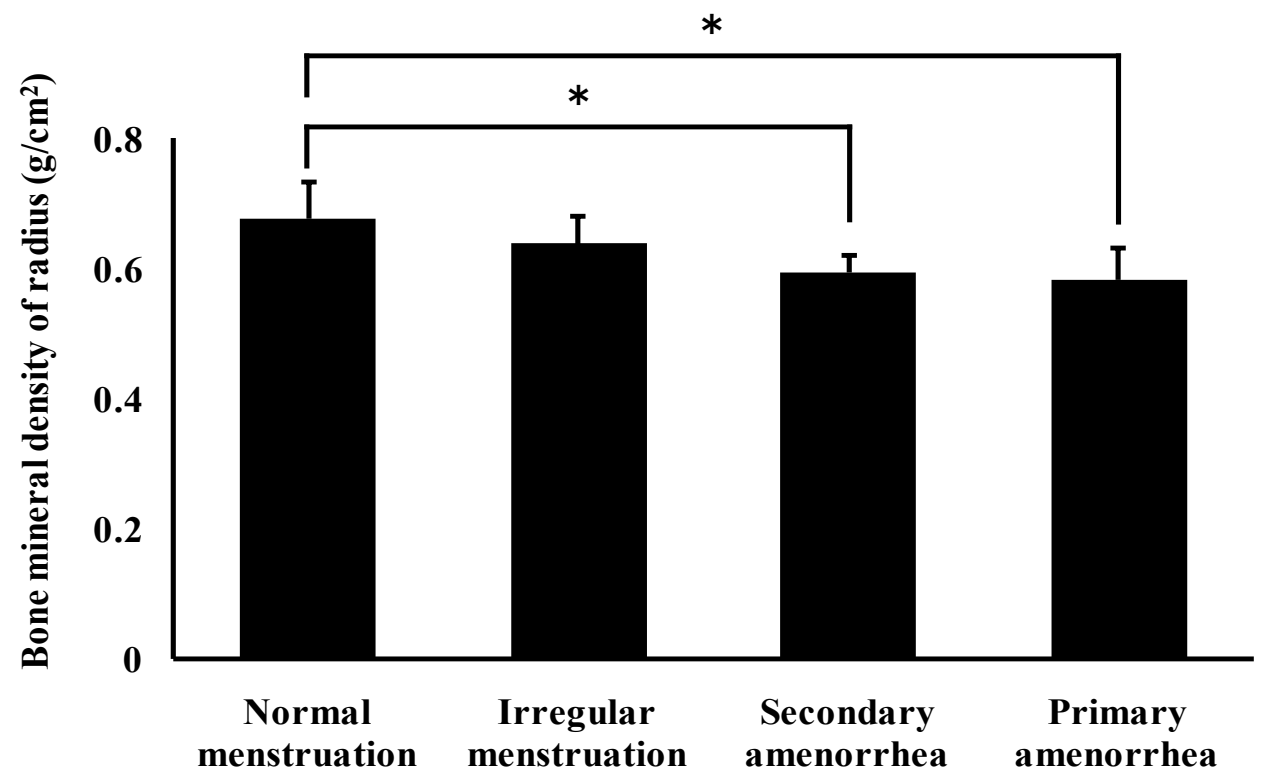

Menstrual condition

Figure 1: Comparison of bone mineral density in radius among menstrual conditions.

Values were mean and standard deviations of bone mineral density in normal menstruation, irregular menstruation, secondary menstruation, and primary amenorrhea, and were compared by one-way analysis of variates, and Tukey test was performed as a post hoc. A p-value below 0.05 compared with normal menstruation $\left(^{*}\right)$, irregular menstruation $\left({ }^{\dagger}\right)$, and secondary menstruation $(\#)$ were significant.

Table 4: Correlation between concentration of bone metabolism markers and bone mineral density in the distal radius.

\begin{tabular}{|l|l|l|}
\hline \multicolumn{2}{|l|}{ Distal radius } \\
\hline & $\rho$ & $p$-value \\
\hline Serum NTx & -0.60 & 0.001 \\
\hline Serum total P1NP & -0.17 & 0.395 \\
\hline Serum pentosidine & -0.59 & 0.001 \\
\hline
\end{tabular}

Spearman's correlation coefficients between bone mineral density in radius and concentrations of bone metabolic markers were calculated in all subjects. lete group compared with controls (Table 3 ).

The distal radial BMD in the athlete group was 0.60 $\pm 0.04 \mathrm{~g} / \mathrm{cm}^{2}$, compared with $0.68 \pm 0.06 \mathrm{~g} / \mathrm{cm}^{2}$ in the control group: ANOVA indicated that BMD was significantly reduced with increased severity of menstrual disorder ( $p=0.002$, Figure 1 ). Also, BMD in subjects with amenorrhea was significantly lower than those who menstruated normally. There were significant relationships between distal radial BMD (estimated by serum estradiol concentration) and both sNTx con- 
Table 5: Comparison of bone metabolism markers and bone quality marker between athlete and control groups, and the proportion with values over the normal range.

\begin{tabular}{|c|c|c|c|c|c|c|}
\hline & \multirow{2}{*}{$\begin{array}{l}\text { Normative } \\
\text { range }\end{array}$} & \multicolumn{2}{|c|}{ Control group $(n=31)$} & \multicolumn{2}{|c|}{ Athlete group $(n=16)$} & \multirow[t]{2}{*}{ p-value } \\
\hline & & Mean & Out of range & Mean & Out of range & \\
\hline $\begin{array}{l}\text { Calcium } \\
\text { (mg/dl) }\end{array}$ & $8.4-10.4$ & $9.5 \pm 0.4$ & $\begin{array}{l}0 \\
(0 \%)\end{array}$ & $10.0 \pm 0.4$ & $\begin{array}{l}2 \\
(12.5 \%)\end{array}$ & $<0.001$ \\
\hline $\begin{array}{l}\text { iPhosphate } \\
\text { (mg/dl) }\end{array}$ & $2.5-4.5$ & $3.9 \pm 0.6$ & $\begin{array}{l}4 \\
(12.9 \%)\end{array}$ & $4.1 \pm 0.4$ & $\begin{array}{l}3 \\
(18.8 \%)\end{array}$ & 0.192 \\
\hline $\begin{array}{l}\text { sNTx } \\
\text { (nM BCE/I) }\end{array}$ & $7.5-24.0$ & $16.4 \pm 3.8$ & $\begin{array}{l}1 \\
(3.2 \%)\end{array}$ & $26.7 \pm 5.8$ & $\begin{array}{l}12 \\
(75.0 \%)\end{array}$ & $<0.001$ \\
\hline $\begin{array}{l}\text { Total P1NP } \\
(\mu \mathrm{g} / \mathrm{l})\end{array}$ & $14.9-68.8$ & $51.4 \pm 17.5$ & $\begin{array}{l}4 \\
(12.9 \%)\end{array}$ & $76.0 \pm 36.8$ & $\begin{array}{l}7 \\
(43.8 \%)\end{array}$ & 0.031 \\
\hline $\begin{array}{l}\text { sPEN } \\
(\mathrm{pmol} / \mathrm{ml})\end{array}$ & $15.6-43.0$ & $21.4 \pm 6.2$ & $\begin{array}{l}0 \\
(0 \%)\end{array}$ & $37.4 \pm 7.8$ & $\begin{array}{l}3 \\
(18.8 \%)\end{array}$ & $<0.001$ \\
\hline
\end{tabular}

The concentration of bone metabolism markers and bone quality markers were compared using the unpaired Mann-Whitney $U$ test. The normal ranges of each bone metabolism marker were as follows: NTx, $7.5-24.0 \mathrm{nM}$ bone collagen equivalents [BCE]/l; total P1NP, 14.9 - $68.8 \mu \mathrm{g} / \mathrm{l}$; pentosidine, 15.6 - $43.0 \mathrm{pmol} / \mathrm{ml}$. A p-value < 0.05 was considered significant.

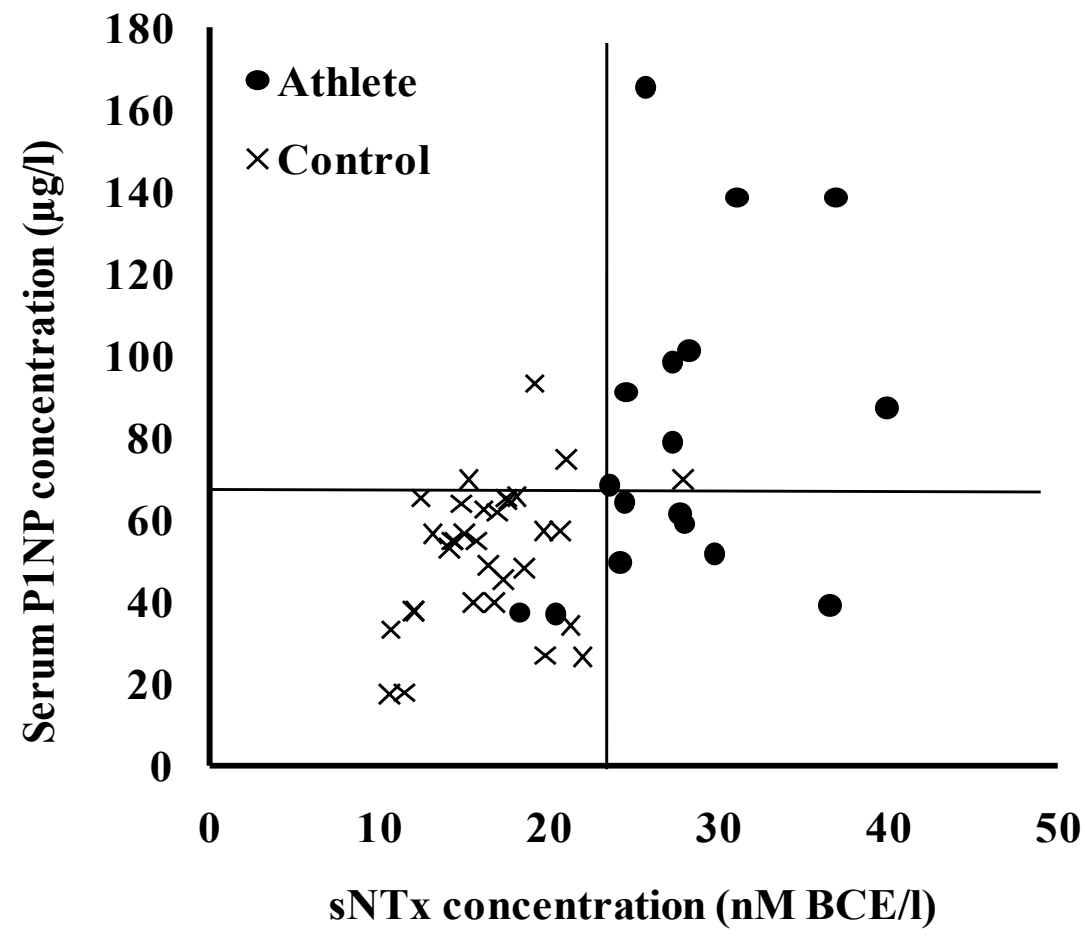

Figure 2: Scatter plot of bone metabolism markers.

Abbreviations: NTx: Type I collagen cross-linked N-telopeptide; P1NP: N-terminal propeptine of procollagen type I. Cut offline was cited from reference data for diagnosis of osteoporosis [23].

centration $(\rho=-0.60, p=0.001)$ and SPEN concentration $(\rho=-0.59, p=0.001$ ) in the athlete group (Table 4).

For indices of bone metabolism, the concentrations of sNTx $(p<0.001)$ and total P1NP $(p=0.010)$ were significantly higher in the athlete group than the control group (Table 5). The sNTx concentration was above the normal range in all athletes (100\%), and serum P1NP was above the normal ranges in eight $(47.1 \%)$ athletes, respectively. For indices of bone quality, the concentration of SPEN in the athlete group was significantly high- er than controls $(p<0.001)$, and was above the normal range in three subjects (17.6\%). There was a positive correlation between sNTx and total P1NP concentrations ( $\rho=0.448, p=0.002$; Figure 2 ).

Multivariate linear regression analysis identified a significant positive correlation between higher SPEN concentration and increasing sNTx concentration $(p=$ 0.030 ), and a negative correlation between higher SPEN concentration and reducing serum estradiol concentration $(p=0.035)$ and serum total P1NP concentration ( $p$ $=0.030$ ). There was no significant relationship between 
Table 6: Correlation coefficients between serum pentosidine concentration and bone metabolism markers.

\begin{tabular}{|l|l|l|l|}
\hline & Correlation coefficients & p-value & Adjusted R $^{\mathbf{2}}$ \\
\hline Age & -0.13 & 0.416 & 0.52 \\
\hline Body mass index & -0.26 & 0.032 & \\
\hline Prolactin & -0.14 & 0.230 \\
\hline Estradiol & -0.28 & 0.035 & \\
\hline Testosterone & 0.16 & 0.167 & \\
\hline Serum NTx & 0.39 & 0.030 & \\
\hline Serum total P1NP & -0.29 & 0.030 & \\
\hline
\end{tabular}

Linear regression analysis was performed with the serum pentosidine concentration as the dependent variable, and age, body mass index, concentration of terminal gonadotropin and bone metabolic markers as independent variables. Values of correlation coefficients indicated standardized coefficients with serum pentosidine concentration, and minus values in coefficients indicated the negative correlation. Abbreviations: NTx: Type I collagen cross-linked N-telopeptide; P1NP: N-terminal propeptine of procolla.

SPEN concentration and serum total P1NP concentration (Table 6).

\section{Discussion}

Our cross-sectional comparison study found that indices of bone absorption and bone formation were significantly higher in female long-distance runners with menstrual disorder than healthy young female volunteers. We also found that there were significant relationships between markers of bone absorption and bone formation. The bone metabolism of female long-distance runners exhibited high turnover but differed from the bone metabolism typical of osteoporosis. We have elected to describe this distinct pattern of bone metabolism as 'complex high turnover', mainly a combination of high bone absorption related to menstrual disorder and high bone formation as a result of repeated microdamage caused by running. We also found that high bone absorption was significantly correlated with deterioration in bone quality reflected by SPEN concentration.

\section{Complex high turnover bone metabolism}

The bone metabolism of female long-distance runners was characterized by high bone absorption and high bone formation, which we defined as a 'complex high turnover' state when associated with menstrual disorder. It is well-recognized that bone metabolism changes to a high turnover state after menopause [26], when diminished estrogen secretion induces an increase in the expression of receptor activation of nuclear factor-KB ligand (RANKL) in osteoclasts, which in turn accelerates bone absorption [27]. This process also induces a weak increase in bone formation ability via the RANK-RANKL pathway [28], but one that is insufficient to shift the bone metabolic balance from the bone absorption responsible for osteoporosis. In the female athletes in our study, higher bone formation ability was induced by the repeated stimulation of running as well as activation of bone absorption by menstrual disorder. Repeated stimulation reportedly promotes bone formation ability [29]. Ultimate- ly, in these elite endurance runners the combination of high bone absorption and bone formation led to a complex high turnover state unlike that seen in postmenopausal osteoporosis.

\section{Problems with complex high turnover}

Complex high turnover bone metabolism would be likely to predispose athletes to stress fracture. Bone fragility reportedly begins with the micro-cracks and voids [30], the accumulation of which cause non-traumatic fracture in osteoporosis [31]. Barr and colleagues reported that accumulation of microdamage is a consistent risk for fracture in dogs, when the number of fracture sites increased when bone metabolism was strongly suppressed by high-dose bisphosphonate administration [32]. High turnover bone metabolism is rarely seen in health young adults, and the bone remodeling system generally acts to repair microdamage when it occurs. However, more rapid bone remodeling leads to the development of wider remodeling spaces, which become weak points. Thus, the repetitive loading of long-distance running may cause substantial microdamage to the lower extremity, resulting in elevated bone formation and pace of bone remodeling. We propose that an excessive state of bone metabolic turnover would likely increase the risk for stress fracture in athletes.

\section{Degradation of bone quality}

We found that the concentration of SPEN, a systemic bone quality marker, rose in parallel with sNTx concentration. Pentosidine is a part of the structure of an Advanced Glycation End product (AGE), and its serum concentration reflects the concentration in collagen in bone. In primary osteoporosis, deterioration in bone quality is induced by age and gonadotropin deficit [18]. Furthermore, oxidative stress, glycation stress related to renal failure and diabetes mellitus all promote excessive production of AGEs [33]. These data support our finding that the SPEN concentration was positively correlated with serum estradiol and SNTx concentrations. Mitome and colleagues reported that accumulation of pentosidine in collagen 
correlated with a reduction in bone formation [33]. Given these findings, it was thought that, of the bone metabolic markers, only those of bone absorption would be significantly correlated with SPEN concentration, essentially the opposite to the negative correlation with bone formation. Increasing SPEN concentration with age is an independent risk factor for reduced bone strength [34]. Shiraki and colleagues have reported the influence of genetic determinants upon impaired bone quality. The hazard ratio for fracture with the combination of the methylenetetrahydrofolate reductase polymorphism (C677T) disorder of bone quality and osteoporosis was 7.21 (95\% confidence interval 4.34-11.97) [35]. Furthermore, in injured sites with micro damage, macrophages produce tumor necrosis factor- $\alpha$ and interleukin-1 $\beta$ [36], which would further reduce bone quality.

\section{Limitations and future directions}

Our study had several limitations besides its small sample size. First, most long-distance runners had menstrual disorders. In previous studies, the proportion of female athletes experiencing menstrual disorder ranged from 3-66\%, compared with $2-5 \%$ in the general female population [37]. The likely explanation is the nature of junior athletics in Japan, where the intensity of physical training required to compete in national competitions is so high that menstrual disorders are very common. Our findings, and those of others, underline the importance of managing menstrual disorder appropriately, as amenorrhea has consistently been identified as a risk factor for stress fracture [38]. Second, we found no significant difference in LH or FSH between the groups, when menstrual disorder would be expected to suppress hypothalamic function. Physiologic cyclical changes in serum gonadotropin concentration may have influenced our results. Third, relatively few of our athletes had experienced stress fracture. While we were able to illuminate the complex high turnover bone metabolism state associated with menstrual disorder in female long-distance runners, our sample was too small to establish whether athletes with stress fractures exhibited the same bone metabolic pattern. Further research is needed to establish the characteristics of bone metabolism in athletes with stress fracture, and the nature of the relationships between complex high turnover, bone quality and stress fracture. A large, prospective cohort study will be needed to identify markers of bone metabolism and quality that predict stress fracture.

Despite these limitations, we found that female long-distance runners with menstrual disorder exhibited a complex high turnover bone metabolism state, consisting of a combination of high bone absorption (caused by menstrual disorder) and high bone formation (caused by microdamage provoked by repeated loading and increased remodeling space) that likely increase the risk for stress fracture. While long-term follow-up and further investigation of symptoms and training intensity are necessary, bone metabolic markers may contribute to our understanding of stress fracture and its risk factors.

\section{Conclusions}

Markers of bone absorption and formation were significantly elevated in female long-distance runners with menstrual disorders compared with healthy young women, and there were positive correlations between the markers. The complex high turnover bone metabolism state that we identified appears to be distinct to female long-distance runners. Furthermore, higher bone absorption impaired bone quality, creating the conditions required for stress fracture.

\section{Conflict of Interest}

This study was supported in a part by Megmilk Snow Brand Co., Ltd. (Tokyo, Japan). The authors have no competing interests to declare.

\section{Acknowledgements}

The authors would like to thank the long-distance runners in Meijo University Women's Ekiden Club, who kindly agreed to participate in this study.

\section{References}

1. Nattiv A, Loucks AB, Manore MM, Sanborn CF, Sundgot-Borgen J, et al. (2007) American College of Sports Medicine position stand. The female athlete triad. Med Sci Sports Exerc 39: 1867-1882.

2. Feicht CB, Johnson TS, Martin BJ, Sparkes KE, Wagner WW Jr (1978) Secondary amenorrhoea in athletes. Lancet 2: $1145-1146$.

3. Boden BP, Osbahr DC (2000) High-risk stress fractures: evaluation and treatment. J Am Acad Orthop Surg 8: 344353.

4. Feingold D, Hame SL (2006) Female athlete triad and stress fractures. Orthop Clin North Am 37: 575-583.

5. Hame SL, LaFemina JM, McAllister DR, Schaadt GW, Dorey FJ (2004) Fractures in the collegiate athlete. Am J Sports Med 32: 446-451.

6. McBryde AM Jr (1985) Stress fractures in runners. Clin Sports Med 4: 737-752.

7. Bachrach LK, Guido D, Katzman D, Litt IF, Marcus R (1990) Decreased bone density in adolescent girls with anorexia nervosa. Pediatrics 86: 440-447.

8. Myburgh $\mathrm{KH}$, Hutchins J, Fataar AB, Hough SF, Noakes TD (1990) Low bone density is an etiologic factor for stress fractures in athletes. Ann Intern Med 113: 754-759.

9. Pepper M, Akuthota V, McCarty EC (2006) The pathophysiology of stress fractures. Clin Sports Med 25: 1-16.

10. Moran DS, Israeli E, Evans RK, Yanovich R, Constantini N, et al. (2008) Prediction model for stress fracture in young female recruits during basic training. Med Sci Sports Exerc 40: $636-644$ 
11. Cann CE, Martin MC, Genant HK, Jaffe RB (1984) Decreased spinal mineral content in amenorrheic women. JAMA 251: 626-629.

12. Ishibashi $\mathrm{Y}$, Okamura $\mathrm{Y}$, Otsuka H, Nishizawa K, Sasaki T, et al. (2002) Comparison of scintigraphy and magnetic resonance imaging for stress injuries of bone. Clin J Sport Med 12: 79-84.

13. Schnackenburg KE, Macdonald HM, Ferber R, Wiley JP, Boyd SK (2011) Bone quality and muscle strength in female athletes with lower limb stress fractures. Med Sci Sports Exerc 43: 2110-2119.

14. Iwamoto J, Takeda $\mathrm{T}$, Uenishi $\mathrm{K}$, Ishida $\mathrm{H}$, Sato $\mathrm{Y}$, et al. (2010) Urinary levels of cross-linked N-terminal telopeptide of type I collagen and nutritional status in Japanese professional baseball players. J Bone Miner Metab 28: 540-546.

15. Yanovich R, Evans RK, Friedman E, Moran DS (2013) Bone turnover markers do not predict stress fracture in elite combat recruits. Clin Orthop Relat Res 471: 1365-1372.

16. NIH Consensus Development Panel on Osteoporosis Prevention, Diagnosis, and Therapy (2001) Osteoporosis prevention, diagnosis, and therapy. JAMA 285: 785-795.

17. Saito M, Fujii K, Soshi S, Tanaka T (2006) Reductions in degree of mineralization and enzymatic collagen cross-links and increases in glycation-induced pentosidine in the femoral neck cortex in cases of femoral neck fracture. Osteoporos Int 17: 986-995.

18. Saito M, Marumo K (2010) Collagen cross-links as a determinant of bone quality: a possible explanation for bone fragility in aging, osteoporosis, and diabetes mellitus. Osteoporos Int 21: 195-214.

19. Wakamatsu K, Sakuraba K, Suzuki Y, Maruyama A, Tsuchiya $Y$, et al. (2012) Association between the stress fracture and bone metabolism/quality markers in lacrosse players. Open Access J Sports Med 3: 67-71.

20. Chiba D, Wada K, Tanaka T, Kumagai G, Sasaki E, et al. (2017) Serum pentosidine concentration is associated with radiographic severity of lumbar spondylosis in a general Japanese population. J Bone Miner Metab 35: 65-72.

21. Sasaki E, Tsuda E, Yamamoto $Y$, Maeda S, Inoue R, et al. (2015) Serum hyaluronic acid concentration predicts the progression of joint space narrowing in normal knees and established knee osteoarthritis - a five-year prospective cohort study. Arthritis Res Ther 17: 283.

22. Sasaki S, Tsuda E, Yamamoto $Y$, Maeda S, Hayashi $Y$, et al. (2013) Change with increasing age in control of the lower limbs during jump-landing in adolescents: a 5-year prospective study. J Orthop Sci 18: 774-781.

23. Nishizawa $Y$, Ohta $H$, Miura $M$, Inaba $M$, Ichimura $S$, et al. (2013) Guidelines for the use of bone metabolic markers in the diagnosis and treatment of osteoporosis (2012 edition). J Bone Miner Metab 31: 1-15.
24. De Souza MJ, Leidy HJ, O'Donnell E, Lasley B, Williams $\mathrm{NI}$ (2004) Fasting ghrelin levels in physically active women: relationship with menstrual disturbances and metabolic hormones. J Clin Endocrinol Metab 89: 3536-3542.

25. Dupont WD, Plummer WD (1998) Power and sample size calculations for studies involving linear regression. Control Clin Trials 19: 589-601.

26. Ivaska KK, Gerdhem P, Väänänen HK, Akesson K, Obrant KJ (2010) Bone turnover markers and prediction of fracture: a prospective follow-up study of 1040 elderly women for a mean of 9 years. J Bone Miner Res 25: 393-403.

27. Leibbrandt A, Penninger JM (2008) RANK/RANKL: regulators of immune responses and bone physiology. Ann N Y Acad Sci 1143: 123-150.

28. Anderson DM, Maraskovsky E, Billingsley WL, Dougall WC, Tometsko ME, et al. (1997) A homologue of the TNF receptor and its ligand enhance T-cell growth and dendritic-cell function. Nature 390: 175-179.

29. Hetland ML, Haarbo J, Christiansen C (1993) Low bone mass and high bone turnover in male long distance runners. $\mathrm{J}$ Clin Endocrinol Metab 77: 770-775.

30. Burr DB, Forwood MR, Fyhrie DP, Martin RB, Schaffler MB, et al. (1997) Bone microdamage and skeletal fragility in osteoporotic and stress fractures. J Bone Miner Res 12: 6-15.

31. Burr DB, Turner CH, Naick $P$, Forwood MR, Ambrosius W, et al. (1998) Does microdamage accumulation affect the mechanical properties of bone? J Biomech 31: 337-345.

32. Burr DB (1993) Remodeling and the repair of fatigue damage. Calcif Tissue Int 53: S75-S80.

33. Mitome J, Yamamoto $H$, Saito M, Yokoyama K, Marumo $\mathrm{K}$, et al. (2011) Nonenzymatic cross-linking pentosidine increase in bone collagen and are associated with disorders of bone mineralization in dialysis patients. Calcif Tissue Int 88: 521-529.

34. Wang X, Shen X, Li X, Agrawal CM (2002) Age-related changes in the collagen network and toughness of bone. Bone 31: 1-7.

35. Shiraki M, Urano T, Kuroda T, Saito M, Tanaka S, et al. (2008) The synergistic effect of bone mineral density and methylenetetrahydrofolate reductase (MTHFR) polymorphism (C677T) on fractures. J Bone Miner Metab 26: 595602.

36. Voll RE, Herrmann M, Roth EA, Stach C, Kalden JR, et al. (1997) Immunosuppressive effects of apoptotic cells. Nature 390: 350-351.

37. Otis CL (1992) Exercise-associated amenorrhea. Clin Sports Med 11: 351-362.

38. Pettersson U, Stalnacke B, Ahlenius G, Henriksson-Larsén K, Lorentzon R (1999) Low bone mass density at multiple skeletal sites, including the appendicular skeleton in amenorrheic runners. Calcif Tissue Int 64: 117-125. 